\title{
Potential effects of endocrine disruption: reproductive tract abnormalities in a 4 year old boy
}

\author{
Cosmina Rimbu ${ }^{1}$, Lisandra Damian ${ }^{1,2}$, Ramona Axinte ${ }^{1}$, Cristina Preda ${ }^{1,2}$, Voichita Mogos ${ }^{1,2}$, Maria Christina \\ Ungureanu $u^{1,2}$. \\ Endocrinology Clinic, "Sf. Spiridon " Emergency Clinical Hospital, Iasi, Romania. \\ Grigore T. Popa", University of Medicine and Pharmacy, Iasi, Romania.
}

Introduction:

Case report:
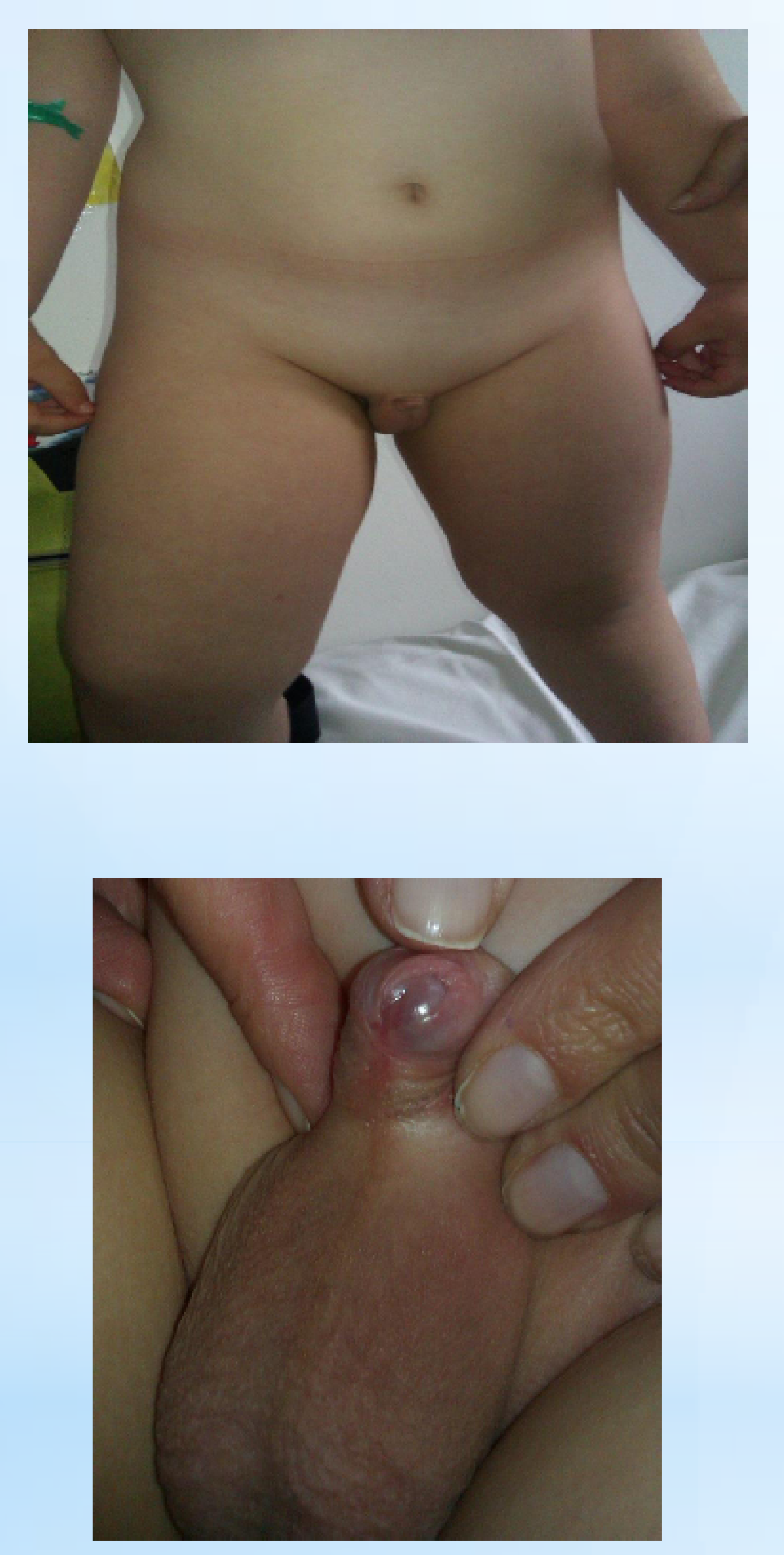

\section{Clinical exam :}

$>$ height: $109 \mathrm{~cm}(+1 \mathrm{SD})$,

$>$ weight: $27 \mathrm{~kg}(+3,5 \mathrm{SD})$,

$>$ micropenis: $3 \mathrm{~cm}(-2,5 \mathrm{SD})$,

$>$ hypospadias,

$>$ bilateral descended testicles,

$>$ normal developed scrotum.

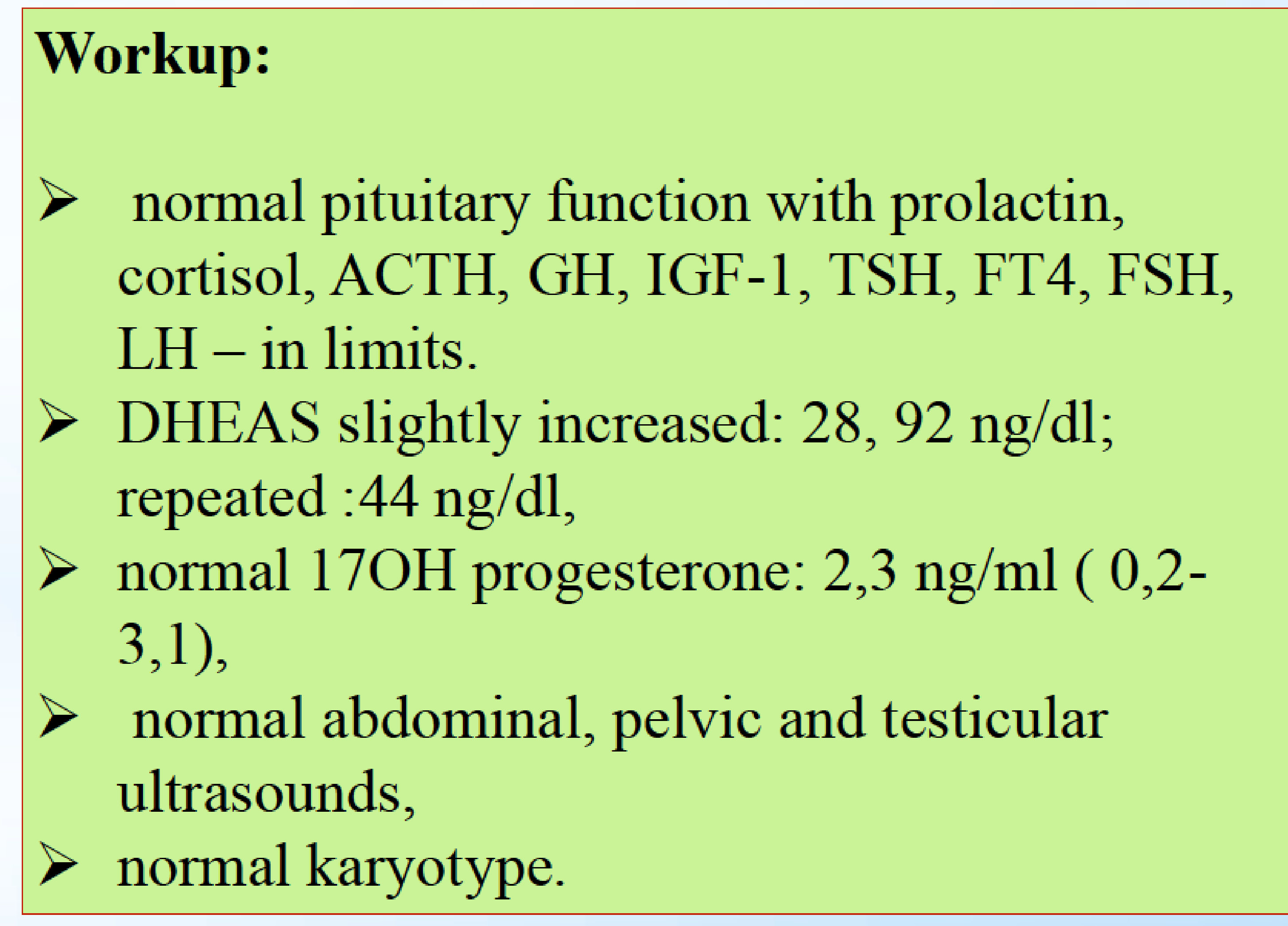

Late-onset 3 beta-hydroxysteroid dehydrogenase deficiency: excluded - androstendione in limits.

5 alpha reductase deficiency: hCG stimulation: DHT $=252 \mathrm{pg} / \mathrm{ml}$ - borderline values, testosterone $/ \mathrm{DHT}=12,77$ infirm this diagnosis.

We took in consideration next diagnostic assumptions:

\section{Conclusions:}

Endocrine disruptor pathology must always remain a diagnostic hypothesis in reproductive tract abnormalities in children.
Androgen partial resistance: the patient has descended testicles; no genetic tests available in our country; good response after androgen treatment.

Intersexuality due to endocrine disruptors.

He received treatment with testosterone enanthate $50 \mathrm{mg}$ at 3 weeks, for 3 months, and his penis increased: $5 \mathrm{~cm}$. He grew $9 \mathrm{~cm}$ in 9 months and bone age improved. Is scheduled for hypospadias correction intervention. 